Gut, 1969, 10, 705-710

\title{
Postmortem study of the frequency of gallstones in patients with cirrhosis of the liver
}

\author{
IAN A. D. BOUCHIER
}

From the Department of Medicine, Royal Free Hospital, London

SUMmARY The frequency of gallstones in cirrhotic and non-cirrhotic patients at necropsy has been determined from a retrospective survey of postmortem records over 15 years. The frequency of gallstones was found to be $29.4 \%$ in the cirrhotic group and $12.8 \%$ in the non-cirrhotic population. Whereas gallstones were twice as frequent in females than males in the general population the sex difference disappeared in cirrhotic patients. Gallstones increased in frequency with age in the general population but this phenomenon was not seen in the cirrhotic group. No one type of cirrhosis was more liable to be associated with gallstones at necropsy. In contrast to the general population bilirubin stones were more frequent in cirrhotics.

There have been a number of studies on the epidemiology and predisposing factors of gallstone disease in an attempt to understand the mechanism of lithogenesis. The prospective Framingham study substantiated the clinical impression that gallstone disease was more frequent in adipose, fertile females. The incidence of the disease increased with age but there was no relation to serum lipid levels (Friedman, Kannel, and Dawber, 1966). Other studies, mainly on the basis of postmortem data, have claimed that gallstone disease is associated with myocardial infarction, diabetes mellitus, hiatal hernia, appendicitis, migraine, cancer of the breast, and pernicious anaemia (Lieber, 1952; van der Linden, 1961; Bergman, van der Linden, and Söderström, 1968). Many of these proposed relationships may reflect a variety of other selective factors and are therefore open to some doubt.

In a previous discussion on lithogenesis (Bouchier and Freston, 1968) it was suggested that a disorder of hepatic bile composition was fundamental to gallstone formation. It is therefore of some interest to know the frequency of gallstone disease in chronic liver disease. There is a lack of recent information about this association and so the present study was undertaken to obtain an idea of the frequency of cholelithiasis in cirrhosis of the liver.

\section{CLINICAL MATERIAL}

The postmortem records were examined of all patients at the Royal Free Hospital during the 15-year period 1951 to 1965 . The age, sex, state of the biliary tract, and the main cause of death were noted. When gall- stones were found a record was made of their site, number, character, and the presence or absence of jaundice. Gallstones were allocated to one of three groups depending on the number of stones: solitary, two to 10 , more than 10, and/or sludge. The type of stone was decided by the naked-eye examination at the time of necropsy and classified as cholesterol, bilirubin (pigment), and mixed. No attempt was made to comment on the appearance of the gallbladder because of postmortem autolytic changes. Patients with a previous cholecystectomy were included in the non-stone population if the biliary tract was clear of stones at necropsy.

Many patients show multiple pathology at necropsy. The major cause of death as given by the pathologist was used to classify the patients into the following groups: death due to cardiovascular, respiratory, gastrointestinal, central nervous system, genitourinary, traumatic, lymphoreticular, haematological, and other diseases. Deaths during the foetal and neonatal period were classed as such and not categorized according to the system involved.

The patients with cirrhosis of the liver were classified according to the type of cirrhosis. This was determined from the clinical features and macroscopic and microscopic appearances of the liver. The following groups were recognized: portal, postnecrotic, alcoholic, primary biliary, secondary biliary, haemochromatosis, cardiac, and other.

The material was classified according to age: neonatal, below 1 year, 1 to 19,20 to 29,30 to 39,40 to 49,50 to 59,60 to 69,70 to 79,80 years and over.

Statistical significance was tested with the chi-square test using Yates' correction (Bailey, 1959).

RESULTS

A total of 4,895 postmortem records were examined 05 
TABLE I

THE FREQUENCY OF GALLSTONES IN CIRRHOTIC AND NON-CIRRHOTIC SUBJECTS AT NECROPSY OVER A 15-YEAR PERIOD

Non-cirrhotic Patients

\begin{tabular}{|c|c|c|c|c|c|c|c|}
\hline Age (yr) & With Stones & Without Stones & Frequency (\%) & & With Stones & Without Stones & Frequency (\%) \\
\hline $\begin{array}{l}1 \text { to } 19 \\
20 \text { to } 29 \\
30 \text { to } 39 \\
40 \text { to } 49 \\
50 \text { to } 59 \\
60 \text { to } 69 \\
70 \text { to } 79 \\
80 \text { and over }\end{array}$ & $\begin{array}{r}0 \\
3 \\
10 \\
26 \\
79 \\
159 \\
161 \\
78\end{array}$ & $\begin{array}{r}99 \\
115 \\
148 \\
397 \\
782 \\
941 \\
708 \\
232\end{array}$ & $\begin{array}{r}0 \\
2 \cdot 5 \\
6 \cdot 3 \\
6 \cdot 2 \\
9 \cdot 2 \\
14 \cdot 4 \\
18 \cdot 5 \\
25 \cdot 2\end{array}$ & $\begin{array}{l}P<0.005 \\
P<0.10>0.05 \\
P<0.01 \\
P<0.005 \\
P<0.001 \\
P<0.001 \\
N / S \\
N / S\end{array}$ & $\begin{array}{r}2 \\
2 \\
5 \\
8 \\
25 \\
20 \\
5 \\
2\end{array}$ & $\begin{array}{r}9 \\
8 \\
13 \\
30 \\
53 \\
36 \\
16 \\
1\end{array}$ & $\begin{array}{l}18 \cdot 4 \\
20 \cdot 0 \\
27 \cdot 8 \\
21 \cdot 2 \\
32 \cdot 1 \\
35 \cdot 7 \\
23 \cdot 8 \\
66 \cdot 7\end{array}$ \\
\hline
\end{tabular}

extending over a period of 15 years. Gallstones were found in 586 patients, an overall frequency of $12 \%$. If the 656 foetal and neonatal deaths and deaths in patients below 20 years of age (in which no gallstones were found) were removed, the frequency of gallstones became $15.5 \%$.

Gallstones were found in 223 of $2,703(8.2 \%)$ males and in 362 of $2,192(16.6 \%)$ females. If deaths in patients below the age of 20 years were excluded the frequency was $9.5 \%$ for males and $19.2 \%$ for females. Thus the frequency of gallstones disease in females at necropsy was twice that of males.

There were 235 patients $(4.8 \%)$ in whom a diagnosis of cirrhosis of the liver was made at necropsy. Sixty-nine of these patients had gallstones, a frequency of $29.4 \%$. Of $128(28.2 \%)$ male cirrhotics 36 had gallstones and 33 of $107(30.8 \%)$ female cirrhotics had gallstones. If the whole group was corrected for deaths below the age of 20 years and for cirrhotic patients the frequency of gallstones in the non-cirrhotic population coming to necropsy was $12.8 \%$ with a prevalence of $8.4 \%$ in males and $18.5 \%$ in females. Thus gallstones were found a non-cirrhotic population coming to necropsy. There was a threefold increase in the frequency of gallstones in male cirrhotics and a twofold increase in female cirrhotics. Thus the sex difference disappeared and gallstones were found with equal frequency in cirrhotics of either sex.

The frequency of gallstones at different ages for cirrhotic and non-cirrhotic subjects is shown in Table I. There was an increase in the frequency of gallstones in cirrhotic compared with non-cirrhotic patients coming to necropsy for all ages below 70 years. This attained statistical significance in all the age groups except in the group 20 to 29 years where $\chi^{2}=3.56$ which was just short of significance at the $5 \%$ level. Over the age of 70 years there was no significant difference between the frequency of stones in the two populations. The frequency of gallstones found at necropsy increased steadily twice as often in a cirrhotic compared with

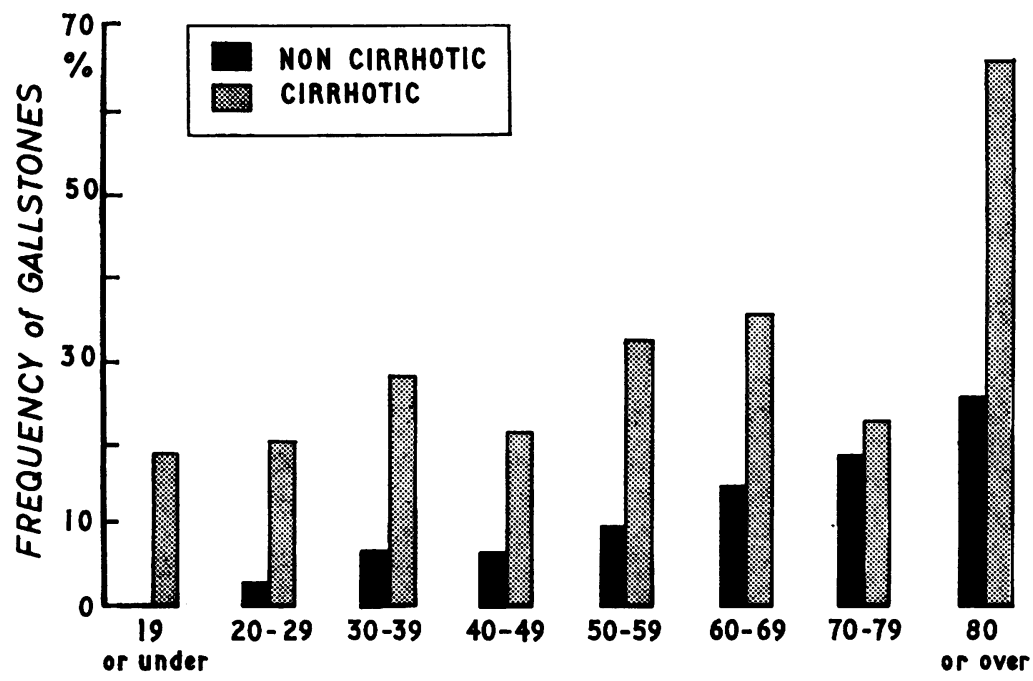

FIG. 1. The frequency of gallstones found at necropsy in non-cirrhotic and cirrhotic patients.

AGE (yrs) 
with age in the non-cirrhotic group. This was not so for cirrhotic patients in whom a prevalence of $18.4 \%$ in the 1-19-year group was comparable to $23.8 \%$ in the 70-79-year group. There were too few cirrhotic patients over the age of 80 to make a meaningful comparison (Fig. 1).

An analysis of the distribution of stones in the different forms of cirrhosis is shown in Table II.

TABLE II

FREQUENCY OF GALLSTONES FOUND AT NECROPSY IN DIFFERENT FORMS OF CIRRHOSIS

\begin{tabular}{|c|c|c|c|}
\hline Type of Cirrhosis & With Stones & Without Stones & Frequency $(\%)$ \\
\hline $\begin{array}{l}\text { Portal } \\
\text { Postnecrotic } \\
\text { Primary biliary } \\
\text { Cardiac } \\
\text { Alcoholic } \\
\text { Haemochromatosis } \\
\text { Secondary biliary } \\
\text { Other }\end{array}$ & $\begin{array}{r}30 \\
20 \\
4 \\
3 \\
5 \\
2 \\
5 \\
0\end{array}$ & $\begin{array}{r}68 \\
58 \\
9 \\
8 \\
9 \\
5 \\
7 \\
2\end{array}$ & $\begin{array}{l}30 \cdot 6 \\
25 \cdot 6 \\
30 \cdot 8 \\
27 \cdot 3 \\
35 \cdot 8 \\
28 \cdot 6 \\
41 \cdot 6 \\
-\end{array}$ \\
\hline
\end{tabular}

The frequency of stones varied from $25.6 \%$ in postnecrotic cirrhosis to $35.8 \%$ in alcoholic cirrhosis. No one form of cirrhosis had a greater prevalence of gallstones at necropsy. The increased frequency of gallstones in secondary biliary cirrhosis was to be expected because cholelithiasis is an important aetiological factor in the genesis of this form of cirrhosis. The patients with primary biliary cirrhosis manifested the typical clinical, biochemical, and histological features of the disease; none of these patients had stones in the common bile duct.

A comment was made on the number of stones found at necropsy in $\mathbf{5 7 8}$ patients and the comparison between the cirrhotic and non-cirrhotic groups is given in Table III. There was no significant difference between the two groups. Cirrhotic patients coming to necropsy have the same number of gallstones as a non-cirrhotic population. More than three-quarters of the patients had multiple stones.

\section{TABLE III}

NUMBER OF GALLSTONES FOUND AT NECROPSY IN CIRRHOTIC AND NON-CIRRHOTIC PATIENTS

\begin{tabular}{lllll}
$\begin{array}{l}\text { No. of } \\
\text { Stones }\end{array}$ & Cirrhotic & $\begin{array}{l}\text { Frequency } \\
(\%)\end{array}$ & $\begin{array}{l}\text { Non- } \\
\text { cirrhetic }\end{array}$ & $\begin{array}{l}\text { Frequency } \\
(\%)\end{array}$ \\
\hline 1 & 11 & $15 \cdot 8$ & 127 & 25.0 \\
2 to 10 & 31 & 44.9 & 208 & 41.0 \\
10 or sludge & 27 & 39.3 & 174 & 34.0
\end{tabular}

The naked-eye appearance of the stones was recorded in 485 necropsies and the analysis of these data is shown in Table IV.Patients with cirrhosis had a significantly greater frequency of bilirubin stones and significantly fewer stones of the mixed variety than the non-cirrhotic population. Cholesterol stones
TABLE IV

A COMPARISON OF THE CHARACTER OF GALLSTONES FOUND AT NECROPSY IN CIRRHOTIC AND NON-CIRRHOTIC PATIENTS

\begin{tabular}{|c|c|c|c|c|}
\hline $\begin{array}{l}\text { Type of } \\
\text { Stone }\end{array}$ & Cirrhotic & $\begin{array}{l}\text { Frequency } \\
(\%)\end{array}$ & $\begin{array}{l}\text { Non- } \\
\text { cirrhotic }\end{array}$ & $\begin{array}{l}\text { Frequency } \\
(\%)\end{array}$ \\
\hline $\begin{array}{l}\text { Cholesterol } \\
\text { Bilirubin }\end{array}$ & $\begin{array}{r}4 \\
43\end{array}$ & $\begin{array}{l}6.3 \\
66.2 \\
P<0.001\end{array}$ & $\begin{array}{l}54 \\
75\end{array}$ & $\begin{array}{l}12.9 \\
17.8\end{array}$ \\
\hline Mixed & 18 & $\begin{array}{l}27.5 \\
P<0.001\end{array}$ & 291 & $69 \cdot 3$ \\
\hline
\end{tabular}

occurred with the same frequency in both groups. The distribution of the stones was the same for males and females in both groups.

Stones and/or sludge were found in the common bile duct in five $(7.2 \%)$ cirrhotic and $34(6.6 \%)$ non-cirrhotic patients. This difference was not statistically significant. In these patients there were 12 $(35.3 \%)$ non-cirrhotics who were icteric at the time of necropsy compared with three $(60 \%)$ of the cirrhotics. The latter group was made up of patients with secondary biliary cirrhosis. None of the cirrhotic patients had undergone cholecystectomy and all were below 70 years of age. A cholecystectomy had been performed in 11 of the non-cirrhotic subjects and 24 of the 34 patients were over 70 years of age.

An analysis was made of patients who died from liver necrosis so that a comparison could be made between two forms of liver disease: cirrhosis, a chronic illness, and liver necrosis, an acute or subacute event. A postmortem diagnosis of acute or subacute liver cell necrosis was made in 34 patients of whom five (14.7\%) had gallstones. A frequency of $14.7 \%$ is similar to that found in the non-cirrhotic population and much lower than in cirrhotic patients. The figures suggested that patients dying in acute or subacute liver failure did not have an increased tendency to form gallstones or alternatively that there had not been time for any such tendency to manifest itself.

The non-cirrhotic population was subdivided according to the major system involved as a cause of death. In contrast to cirrhotic patients it was often impossible to ascribe death to any single cause, two or three major pathological processes frequently existing in one patient. No accurate assessment could be made of the frequency of gallstones related to disease in the different systems.

\section{DISCUSSION}

There are many causes for bias in undertaking a mass comparison (Mainland, 1953). The present data must therefore be interpreted in the knowledge of the defects inherent in all such studies. The population attending this hospital is not representative of the general population of sick people and there is a 
further element of selection in the large number of cirrhotic patients in this series which reflects the clinical interest of the academic medical unit.

Cirrhotic subjects coming to necropsy showed an increased frequency of gallstone disease, the prevalence of $29.4 \%$ being double that of the noncirrhotic population. In cirrhotic males a frequency of $28.2 \%$ was three times that for non-cirrhotic males; in females the frequency of $30.8 \%$ was double that for the control group. In a postmortem study Davidson (1962) found the frequency of stones in cirrhotics to be $22.6 \%$ compared with $14.2 \%$ in a control group. On the other hand, Lieber (1952) recorded frequencies of $9.1 \%$ in male cirrhotics and $22.2 \%$ in female cirrhotics which were only slightly greater than the figures for the general population. Wantz and Payne (1961) found that $26.7 \%$ of patients undergoing a portocaval anastomosis had cholelithiasis. It is not possible from this study to make any comments on the clinical problems posed by gallstones in cirrhotic patients. The impression is that the gallstones seldom give rise to symptoms despite the occurrence of stones in nearly one in three cirrhotics at necropsy.

Berkson (1946) showed that the frequency with which a combination of diseases occurs in a hospital popuiation may give an erroneous impression of the frequencies which occur in the total population of patients from which the hospital group has been drawn. In discussing the principle of competing selection rates Mainland (1953) stated that if there is no association between diseases in the total population, a spurious association will arise in the hospital group between the disease group with the lowest probability of admission and the third disease. On the other hand if an association is demonstrated, despite a bias working in the opposite direction, such an association can be accepted as proven, at least as far as competition among selection rates. Thus in the comparison between cirrhosis and the remainder of the hospital population, the cirrhotics who have a frequency of gallstone disease greater than the control population, do not have a lower fatality rate than that of controls. Horn (1956) argued that a more accurate description of gallstones in the population would be given by a combination of necropsy figures with statistics from living patients. It is possible that very few cirrhotics have gallstones removed at an operation whereas cholecystectomy is a relatively common operation in the non-cirrhotic population, but it seems unlikely that this bias would give rise to such a big difference in frequency.

A frequency of $12 \%$ for the presence of gallstones in the whole group, with $8.2 \%$ in males and $16.6 \%$ in females, compared favourably with the results of
TABLE V

A COMPARISON OF THE FREQUENCY OF GALLSTONES FOUND AT NECROPSY FROM THE DATA OF VARIOUS AUTHORS

\begin{tabular}{llcl} 
& \multicolumn{3}{l}{ Frequency of Gallstones (\%) } \\
\cline { 2 - 4 } Author & Whole Group & Males & Females \\
\hline Rovsing (1924) & 8 & 4.9 & $11 \cdot 27$ \\
Ehnmark (1939) & 11 & $5 \cdot 5$ & $17 \cdot 2$ \\
Torvik and & $19 \cdot 5$ & 12.7 & $27 \cdot 1$ \\
$\quad$ Høivik (1960) & & 8.2 & 16.6 \\
Present series & 12.0 & &
\end{tabular}

other authors (Table V). If the deaths due to cirrhosis of the liver and deaths in patients under 20 years of age are removed the figures are $12.8 \%, 8.4 \%$, and $18.5 \%$ for the whole groups, males, and females respectively. There is a tendency for the prevalence of gallstones to increase with age (Rovsing, 1924; Ehnmark, 1939; Horn, 1956; Friedman et al, 1966) and the results on the non-cirrhotic population in the present study supported this observation. On the other hand this phenomenon was not seen in the cirrhotic group which had a similar frequency at all ages up to 79 years. Gallstones were significantly more frequent in cirrhotics compared with the noncirrhotic population at all age groups up to 69 years.

Not unexpectedly there was a high frequency of stones in patients with secondary biliary cirrhosis coming to necropsy. The cause for the prolonged extrahepatic obstruction was usually a biliary stricture or gallstones or a combination of these two factors. Surprisingly none of the patients with secondary biliary cirrhosis and common duct stones at necropsy had undergone a cholecystectomy. There was no difference in the frequency of gallstones in all others forms of cirrhosis, the values varying from $35.8 \%$ in alcoholic cirrhosis to $25.6 \%$ in postnecrotic cirrhosis. Davidson (1962) found 39 cases of gallstone disease in 118 alcoholic cirrhotics, and 43 patients with gallstones in 244 nonalcoholics coming to necropsy, giving frequencies of $33.1 \%$ and $17.6 \%$ respectively. The data from the present study were not in agreement, the frequency of gallstones in alcoholic cirrhotics being $35.8 \%$ and $40.8 \%$ in the nonalcoholic cirrhotics. Davidson's arguments why there might be an increased frequency of gallstones in alcoholics are hard to uphold and there does not seem to be any good reason why alcoholics should be more prone to develop gallstones.

The frequency of stones in the common bile duct is difficult to establish and figures will vary depending upon whether the data have been obtained at operation or necropsy. Surgical figures will reflect very much the attitude of the surgeon towards operative cholangiography and exploration of the common 
bile duct. Glenn and Beil (1964) reported the incidence of common bile duct stones at operation to be $10 \%$ over a 30 -year period and an examination of the data of Madden, Vanderheyden, and Kandalaft (1968) produced a similar figure for their 18 years' experience. Common bile duct stones were found in $6 \%$ of patients with gallstones at necropsy in this study and occurred with equal frequency in the cirrhotic and non-cirrhotic groups. The present study supported the previous observation (Edholm and Jonsson, 1962; Glenn and Beil, 1964) that gallstones in the common bile duct are relatively more frequent in patients aged over 70 years. Only one third of these patients had undergone a previous cholecystectomy.

The morphological grouping of the stones in this study is simple and correlates with the biochemical composition of gallstones (Madden et al, 1968). However, the value of classifying gallstones according to their biochemical composition has been questioned (Lancet, 1968). The frequencies of the different varieties of gallstones in this series-12.9\% cholesterol, $17.8 \%$ bilirubin, and $69.3 \%$ mixed-compared well with the values given by Horn (1956) of $15.1 \%, 36.4 \%$, and $48.5 \%$ respectively. The significantly increased frequency of bilirubin stones $(66.2 \%)$ found in the cirrhotics in this study is of considerable interest and may indicate a possible factor in gallstone formation in these patients.

The reason for the increased frequency of gallstones in cirrhotic patients is unknown. Gallstones with a high pigment content traditionally are associated with chronic haemolytic states (Juniper, 1958; Webster and Caira, 1959) and chronic mild haemolysis is known to occur in hepatic cirrhosis (Jandl, 1955; Cawein, Hagedorn, and Owen, 1960). Jones, Weinstein, Ettinger, and Capps (1955) commented on an association between chronic haemolysis in liver disease and cholelithiasis, and the present finding of an increased frequency of bilirubin stones in cirrhotics is indirect support for the hypothesis that chronic haemolysis contributes to lithogenesis in these patients. A reduction in the trihydroxy/dihydroxy bile salt ratio has been reported in lithogenic bile (Tamesue and Juniper, 1967) but there is little information about the bile salts in cirrhosis. Osborn, Wooton, da Silva, and Sherlock (1959) reported the ratio of these bile acids in the serum to be lower in portal cirrhosis but not in biliary cirrhosis. Sjövall (1960) found that although the deoxycholic acids were reduced in cirrhosis the cholic acid portion was also decreased so that chenodeoxycholic acid (a dihydroxy bile acid) comprised about two-thirds of the total bile acids in the bile. Cirrhotic patients have a reduction in glycine conjugated bile acids but this is not thought to predispose to gallstone formation. An increase in gallstone formation is not a phenomenon peculiar to liver disease per se, for patients with acute and subacute liver failure did not differ from the non-cirrhotic population in the prevalence of gallstones. On the other hand it can be argued that such patients did not live long enough for any biochemical abnormalities in the bile to lead to gallstones forming. At present it is only possible to speculate about the biochemical alterations in the bile of cirrhotic patients which might be significant in lithogenesis and this study serves to emphasize the need for a detailed analysis of the physiochemical properties of the bile from patients with liver disease.

I wish to thank Professor K. R. Hill for permitting access to the postmortem records.

\section{REFERENCES}

Bailey, N. T. J. (1959). Statistical Methods in Biology. English University Press, London.

Bergman, F., van der Linden, W., and Söderström, J. (1968). The connection between myocardial infarction and gallstones in an autopsy series. Acta path. microbiol. scand., 73, 559-564.

Berkson, J. (1946). Limitations of the application of fourfold table analysis to hospital data. Biomet. Bull., 2, 47.

Bouchier, I. A. D., and Freston, J. W. (1968). The aetiology of gallstones. Lancet, 1, 340-344.

Cawein, M. J. III, Hagedorn, A. B., and Owen, C. A., Jr (1960). Anemia of hepatic disease studied with radiochromium. Gastroenterology, 38, 324-331.

Davidson, J. F. (1962). Alcohol and cholelithiasis: a necropsy survey of cirrhotics. Amer. J. med. Sci., 244, 703-705.

Edholm, P., and Jonsson, G. (1962). Bile duct stones related to age and duct width. Acta chir. scand., 124, 75-79.

Ehnmark, E. (1939). The gallstone disease: a clinical-statistical study. Ibid., suppl., 57.

Friedman, G. D., Kannel, W. B., and Dawber, T. R. (1966). The epidemiology of gallbladder disease: observations in the Framingham study. J. chron. Dis., 19, 273-292.

Glenn, F., and Beil, A. R., Jr (1964). Choledocholithiasis demonstrated at 586 operations. Surg. Gynec. Obstet., 118, 499-506.

Horn, G. (1956). Observations on the aetiology of cholelithiasis. Brit. med. J., 2, 732-737.

Jandl, J. H. (1955). The anemia of liver disease: observations on its mechanism. J. clin. Invest., 34, 390-404.

Jones, P. N., Weinstein, I. M., Ettinger, R. H., and Capps, R. B. (1955). Decreased red cell survival associated with liver disease. Arch. intern. Med., 95, 93-102.

Juniper, K., Jr (1958). The relationship of a biliary lipoprotein 'complex' to some theories of gallstone formation. Amer. Surg. 24, 45-56.

Lancet (1968). Classification of human gallstones, 1, 1416.

Liefer, M. M. (1952). The incidence of gallstones and their correlation with other diseases. Ann. Surg., 135, 394-405.

Madden, J. L., Vanderheyden, L., and Kandalaft, S. (1968). The nature and surgical significance of common duct stones. Surg. Gynec. Obstet., 126, 3-8.

Mainland, D. (1953). The risk of fallacious conclusions from autopsy data on the incidence of diseases with applications to heart disease. Amer. Heart, J., 45, 644-654.

Osborn, E. C., Wooton, I. D. P., da Silva, L. C., and Sherlock, S. (1959). Serum-bile-acid levels in liver disease. Lancet, 2 , 1049-1053.

Rovsing, T. (1924). Quoted by A. J. H. Rains in 1964. Gallstones: Causes and Treatment. Heinemann, London.

Sjövall, J. (1960). Bile acids in man under normal and pathological conditions. Clin. chim. Acta., 5, 33-41. 
Tamesue, N., and Juniper, K., Jr (1967). Concentrations of bile salts at the critical micellar concentration of human gallbladder bile. Gastroenterology, 52, 473-479.

Torvik, A., and Høivik, B. (1960). Gallstones in an autopsy series. Acta. chir, scand, 120, 168-174.

van der Linden, W. (1961). Some biological traits in female gallstone- disease patients. Ibid., Supplement, 269.

Wantz, G. E., and Payne, M. A. (1961). Experience with portacaval shunt for portal hypertension. New Engl. J. Med., 265, 721-728.

Webster, D. R., and Caira, E. G. (1959). Changing concepts of gallstone formation. Amer. Surg., 25, 12-17. 